\title{
KARAKTERISKTIK BACKSCATTER CITRA ALOS PALSAR POLARISASI HH DAN HV TERHADAP PARAMETER BIOFISIK HUTAN DI SEBAGIAN TAMAN NASIONAL KERINCI SEBLAT
}

\author{
Nirmawana Simarmata ${ }^{1}$, Hartono ${ }^{2}$, Sigit Heru Murti ${ }^{3}$ \\ ${ }^{1}$ Program Studi Teknik Geomatika, Institut Teknologi Sumatera, Lampung, Indonesia \\ 2Program Studi Penginderaan Jauh, Universitas Gadjah Mada, Yogyakarta, Indonesia \\ ${ }^{3}$ Program Studi Penginderaan Jauh, Universitas Gadjah Mada, Yogyakarta, Indonesia
}

\begin{abstract}
Synthetic Aperture Radar (SAR) is one kind of an active remote sensing system, utilizing microwave to records the earth surface. One of the SAR's satellites is ALOS PALSAR which is capable of penetrating clouds so that the underlying objects can be identified. ALOS PALSAR has a polarization system operating with single beam polarization ( $H H$ or $H V)$, dual polarization $(H H+H V$ or $V V+V H)$ and full polarization $(H H+H V+V H+V V)$. This study aims to use the backscatter value of ALOS PALSAR's image for monitoring and mapping the forest. The Utilization of ALOS PALSAR imagery to measure forest biophysical parameters and saturation levels identified based on backscatter sensitivity. Image extraction is done through image calibration where the digital value is converted to sigma naught backscatter value then the result of calibration unit is changed to decibels. Backscatter sensitivity depends on forest structure which can affect scattering mechanism. The backscatter value is also influenced by humidity and weather dynamics which can also affect the dielectric constant. The result of accurate classification of land use polarization fall in $\mathrm{HH}$ accuracy of $62,4 \%$. Whereas for HV polarization accuracy obtained equal to $74,88 \%$.
\end{abstract}

Keywords: SAR, Backscatter, Sigma Naught, ALOSPALSAR, Single Beam Polarization

\section{Pendahuluan}

Hutan tropis mempunyai keanekaragaman vegetasi yang sangat bervariasi namun dalam pengelolaannya sering tidak memperhatikan kelestarian dan keseimbangan antar ekosistem di dalamnya. Kebutuhan terhadap lahan sering menjadi masalah karena mengakibatkan sering terjadinya perubahan penggunaan lahan yang dapat meningkatkan kerusakan hutan. Selain itu perubahan penggunaan lahan juga mempercepat terjadinya degradasi dan deforestasi hutan. Salah satu kawasan hutan di Indonesia yang mengalami perubahan penggunaan lahan yang cukup mengkhawatirkan adalah Taman Nasional Kerinci Seblat (TNKS) [1]. Kerusakan areal kawasan hutan TNKS ini terjadi di empat provinsi yakni di kawasan Sumatera Barat, Jambi, Bengkulu dan Sumatera Selatan. Di Sumatera Barat, kerusakan areal TNKS mencapai ribuan hektar. Kerusakan lahan hutan terjadi akibat perambahan dan adanya lahan kritis di Kabupaten Solok seluas 185 hektar, Kabupaten Solok Selatan seluas 380 hektar dan Kabupaten Pesisir Selatan seluas 500 hektar [1].

Berdasarkan permasalahan di atas kelihatannya program rehabilitasi perlu segera dilakukan, dan untuk menunjang program rehabilitasi ini antara lain diperlukan peta kerusakan hutan (deforestasi) di empat kawasan taman nasional tersebut. Peta kerusakan hutan dapat dibuat dengan cara mengambil data hasil analisis perubahan tutupan lahan di sejumlah kawasan tersebut sebagai data masukan. Sementara itu hasil analisis perubahan tutupan lahan dapat diperoleh dari hasil interpretasi data tutupan lahan dan penggunaan lahan dengan memanfaatkan citra satelit. Perkembangan teknologi penginderaan jauh telah menunjukkan bahwa deforestasi dapat digambarkan dengan nyata melalui hasil pencitraan sistem satelit. Sehingga untuk saat ini teknologi penginderaan jauh merupakan salah satu pendekatan terbaik untuk mengklasifikasikan kelas penggunaan lahan di tingkat regional ketika data tegakan hutan di lapangan sulit diperoleh.

Data citra penginderaan jauh yang digunakan untuk keperluan interpretasi dan analisis tegakan hutan atau untuk keperluan lainnya dapat berupa citra optik maupun non-optik dengan segala kelebihan dan kekurangan yang ada pada masing-masing jenis citra. Citra optik sensitif terhadap gangguan atmosfer namun memiliki resolusi spasial menengah hingga tinggi sedangkan citra non-optik bebas dari gangguan atmosfer namun resolusi spasialnya lebih rendah. Data citra non-optik dapat dihasilkan dari beberapa panjang gelombang berbeda-beda yaitu band $\mathrm{Ka}, \mathrm{K}, \mathrm{Ku}, \mathrm{X}, \mathrm{C}, \mathrm{S}$, L, dan $\mathrm{P}$ dengan nilai panjang gelombang berkisar antara $1.18-100 \mathrm{~cm}$ yang mempunyai penetrasi berbeda-beda pula [2] 
[5]. Penetrasi band $\mathrm{K}$ dan $\mathrm{S}$ hanya mampu menembus bagian atas kanopi, band $\mathrm{L}$ dapat menembus kanopi hingga ke lantai hutan dan mempunyai karakteristik backscatter yang dapat dimanfaatkan untuk menggambarkan dimensi biofisik tegakan, sedangkan band $\mathrm{P}$ dapat menembus hingga ke dalam tanah sehingga dapat dimanfaatkan antara lain untuk mendeteksi struktur batuan geologis.

Salah satu jenis satelit non-optik yang dikenal sekarang ini adalah ALOS PALSAR (Advanced Land Observing Satellite - Phased Array Type L-band Synthetic Aperture Radar). Sensor ALOS PALSAR merupakan pengembangan dari sensor SAR (Synthetic Aperture Radar) yang dikembangkan oleh JAXA (Japan Aerospace Exploration Agency) menggunakan frekuensi L-band (frekuensi pusat 1270 $\mathrm{MHz}$ atau $23.6 \mathrm{~cm}$ ) dengan resolusi 50 meter [4]. ALOS PALSAR memiliki sistem polarisasi yang beroperasi dengan moda fine beam (berkas halus) single polarization $(\mathrm{HH} /$ horisontal - horisontal atau $\mathrm{HV} /$ horisontal - vertikal), dual polarization $(\mathrm{HH}+\mathrm{HV}$ atau $\mathrm{VV}+\mathrm{VH})$ dan full polarization $(\mathrm{HH}+\mathrm{HV}+\mathrm{VH}$ $+\mathrm{VV})$.

Polarisasi HH mempunyai karakteristik yang berbeda dengan polarisasi HV. Polarisasi HH cenderung digunakan untuk daerah yang datar hingga landai, sedangkan polarisasi HV memiliki kelebihan untuk kawasan yang relatif miring dan daerah bervegetasi. Kawasan datar yang bervegetasi lebih peka terhadap polarisasi HV karena adanya diffuse reflection (pantulan menyebar) dari objek vegetasi. Hal ini menunjukkan bahwa citra ALOS PALSAR dapat dimanfaatkan untuk memantau dan memetakan kawasan hutan baik pada topografi datar, landai, miring maupun bergunung. Karena kemampuan band $L$ yang dapat menembus kanopi hutan maka sensitivitas band $L$ lebih cocok digunakan untuk mengidentifikasi parameter biofisik hutan seperti volume biomassa dibandingkan dengan citra yang memiliki panjang gelombang lebih pendek. Pengolahan citra ALOS PALSAR dilakukan melalui ekstraksi citra dimana nilai digital diubah menjadi nilai backscatter sigma naught kemudian hasil kalibrasi satuannya diubah menjadi satuan desibel $(\mathrm{dB})$. Untuk melakukan pengolahan citra ALOS PALSAR pada penelitian ini menggunakan persaman Normalized Radar Cross Section (NRCS) [4] [8].

\section{Gambaran Umum Lokasi Penelitian}

Penelitian ini mengkaji sebagian kawasan TNKS yang berada di Kabupaten Pesisir Selatan dan Kabupaten Solok. Secara geografis, lokasi penelitian terletak antara $676015 \mathrm{mT}$ (meter timur) $716911 \mathrm{mT}$, dan $9881931 \mathrm{mS}$ (meter selatan) - 9811053mS. Lihat Gambar 1.

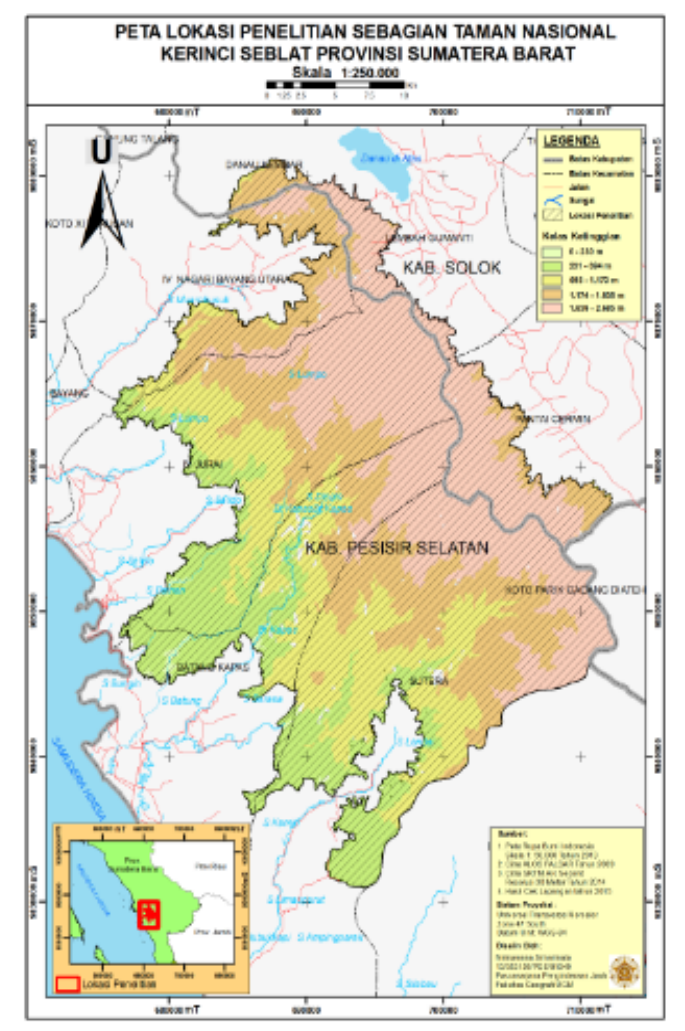

Gambar 1: Peta Batas Wilayah Penelitian 
Metode penelitian dilakukan dalam beberapa tahapan yaitu pengolahan tahap awal citra (image preprocessing) berupa transformasi geometrik, kemudian tahap ekstraksi citra, dan klasifikasi citra.

\subsection{Pengolahan Citra Digital}

Seperti telah diuraikan sebelumnya penelitian ini menerapkan pendekatan multipolarisasi sesuai dengan karakteristik citra yang terdiri atas polarisasi HH dan HV. Konsep multipolarisasi umumnya diterapkan pada citra radar dimana gelombang yang dipancarkan dari antena dipolarisasikan dengan sistem filter tertentu sehingga gerakannya dapat mengikuti arah horisontal $(\mathrm{H})$ atau arah vertikal $(\mathrm{V})$ [5]. Pendekatan multipolarisasi ini diharapkan dapat membantu meningkatkan kemampuan dalam melakukan interpretasi citra.

Seperti juga telah dijelaskan sebelumnya, citra satelit yang digunakan dalam penelitian ini adalah citra ALOS PALSAR Resolusi 50 meter sebagai data primer dengan memanfaatkan nilai backscatter. Dalam pengimplementasiannya, proses transformasi geometrik dilakukan menggunakan dua polarisasi yang terdapat dalam citra ALOS PALSAR (Polarisasi HH dan HV). Tahapan pelaksanaan penelitian yang dilakukan terdiri atas pengolahan citra digital meliputi transformasi geometrik, klasifikasi citra dan ekstraksi nilai backscatter. Lihat Gambar 2.

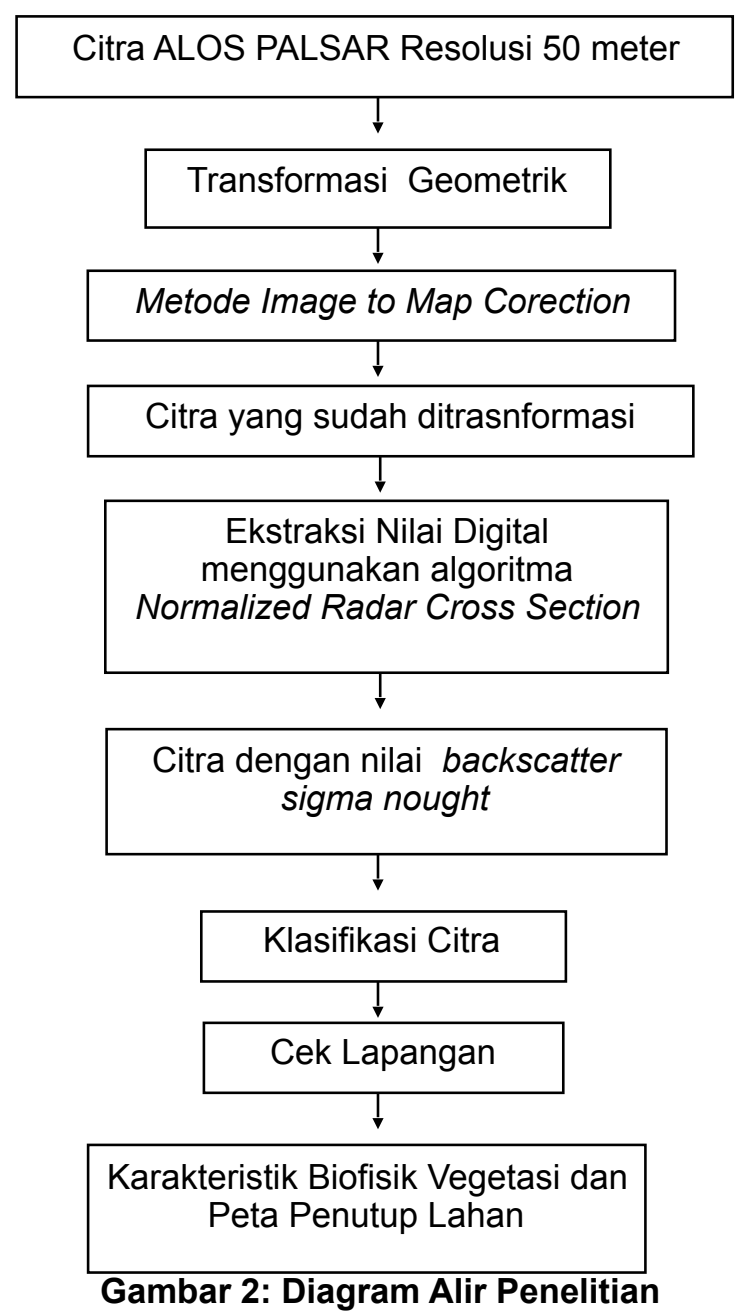

\subsubsection{Transformasi Geometrik}

Citra ALOS PALSAR, seperti halnya jenis citra radar lainnya, pada dasarnya masih memiliki berbagai distorsi/kesalahan. Pada citra ALOS PALSAR terdapat distorsi yang disebabkan oleh sistem pengakuisisian data yang dilakukan yang arahnya menyamping (side looking imaging geometry) dan juga adanya efek perbedaan tinggi berbagai objek di permukaan bumi. Pada umumnya setiap pengolahan citra digital selalu dilakukan transformasi geometrik namun dalam penelitian ini citra ALOS PALSAR yang diperoleh sudah pada level 1.5 yang berarti citra tersebut telah dikoreksi secara geometrik dan radiometrik. Namun demikian masih perlu dilakukan transformasi geometrik lainnya dengan menambah sejumlah GCP (Ground Control Point) untuk mentransformasikan citra dari sistem 
koordinat geografis yang dipakai pada sistem 1.5 ke sistem koordinat TM6/UTM. Transformasi dilakukan dengan metode image to map rectification yang mengidentifikasi posisi/koordinat masingmasing GCP pada citra berdasarkan posisi sebenarnya pada peta RBI. Transformasi koordinat ini akan menghasilkan distorsi atau penyimpangan pada setiap GCP.

Untuk mengetahui ketelitian hasil transformasi geometrik yaang dilakukan berdasarkan distorsi atau penyimpangan pada setiap GCP, kemudian dihitung nilai RMSE (Root Mean Square Error) yang diperoleh dengan menggunakan persamaan 2.1 [3]:

$$
\mathrm{RMS}_{\text {orror }}=\sqrt{\left(\mathrm{x}^{\prime}-\mathrm{x}_{\text {orig }}\right)^{2}+\left(\mathrm{y}^{\prime}-\mathrm{y}_{\text {orig }}\right)^{2}}
$$

dimana:

$$
\begin{array}{ll}
\text { Xorig dan yorig } & \text { : koordinat GCP hasil bacaan pada pete RBI } \\
\mathrm{x}^{\prime} \text { dan } \mathrm{y}^{\prime} & : \text { koordinat hasil hitungan pada citra [3] }
\end{array}
$$

\subsubsection{Ekstraksi Nilai Digital Citra}

Ekstraksi citra dilakukan dengan cara mengubah nilai digital (DN) menjadi citra dengan nilai backscatter sigma nought $\left(\sigma^{\circ}\right)$ yang menghasilkan nilai koefisien backscatter pada tiap piksel citra. Sigma naught $\left(\sigma^{\circ}\right)$ merupakan nilai hamburan balik yang telah mengalami proses normalisasi yang sudah sesuai dengan koordinat peta. Nilai sigma naught $\left(\sigma^{\circ}\right)$ ini merepresentasikan ukuran piksel yang mengacu ke permukaan tanah [4]. Adapun pengolahan data untuk memperoleh nilai backscatter digunakan persamaan Normalized Radar Cross Section (NRCS) dengan rumus 2.2.

$$
\sigma_{(1.5)}^{\circ}=10^{*} \log 10\left(\mathrm{DN}^{2}\right)+\mathrm{CF}
$$

$$
\begin{array}{ll}
\text { dimana: } & \\
\sigma^{\circ} & \text { : sigma nought/ koefisien backscatter pada tiap piksel } \\
\text { DN } & : \text { nilai digital } \\
\text { CF } & : \text { konstanta kalibrasi, yaitu }-83,2(\mathrm{HH}) \text { dan }-80,2(\mathrm{HV})
\end{array}
$$

\subsubsection{Klasifikasi Citra}

Klasifikasi citra ALOS PALSAR dilakukan dengan tujuan agar dapat membedakan jenis-jenis vegetasi pada kawasan penelitian. Proses klasifikasi diawali dengan pemilihan sampel yang akan dikelaskan sesuai kenampakan pada citra. Jenis klasifikasi yang digunakan adalah klasifikasi terawasi (supervised classification) dengan algoritma maximum likelihood classification. Sampel ditentukan berdasarkan kelompok piksel dengan memperhatikan tingkat homogenitasnya.

Hasil klasifikasi kemudian digeneralisasi dengan memanfaatkan majority filter (filter mayoritas) yang bertujuan untuk menghilangkan piksel-piksel terasing (unclassified pixel). Dengan memanfaatkan filter mayoritas yang memiliki dimensi kernel 3x3 dan 5x5 diharapkan akan diperoleh hasil klasifikasi yang optimal [7] [10].

Skema klasifikasi penggunaan lahan yang digunakan dapat dilihat pada Tabel 1.

Tabel 1. Skema klasifikasi penggunaan lahan

\begin{tabular}{lll}
\hline No & Habitat & Karakteristik \\
\hline 1 & $\begin{array}{l}\text { Hutan dataran rendah (lowland } \\
\text { forest) }\end{array}$ & Berada pada ketinggian $150-200$ mdpl \\
2 & Hutan perbukitan (hill forest) & $\begin{array}{l}\text { Ketinggian 300- } 800 \mathrm{mdpl} \text { dengan topografi yang } \\
\text { bervariasi termasuk dataran rendah/hutan } \\
\text { perbukitan dan lembah }\end{array}$ \\
3 & Hutan montana (montane forest) & $\begin{array}{l}\text { Berada di ketinggian antara } 800-2300 \text { mdpl } \\
\text { dengan tinggi kanopi } 35-45 \mathrm{~m} \text { dan kanopi } \\
\text { setinggi 25-30 m }\end{array}$ \\
\hline
\end{tabular}




\section{Hasil dan Analisis}

\subsection{Hasil Transformasi Citra}

Pada penelitian ini, orde transformasi geometrik yang digunakan merupakan orde 3 dengan jumlah GCP sebanyak 10 titik yang tersebar seperti pada Gambar 3.

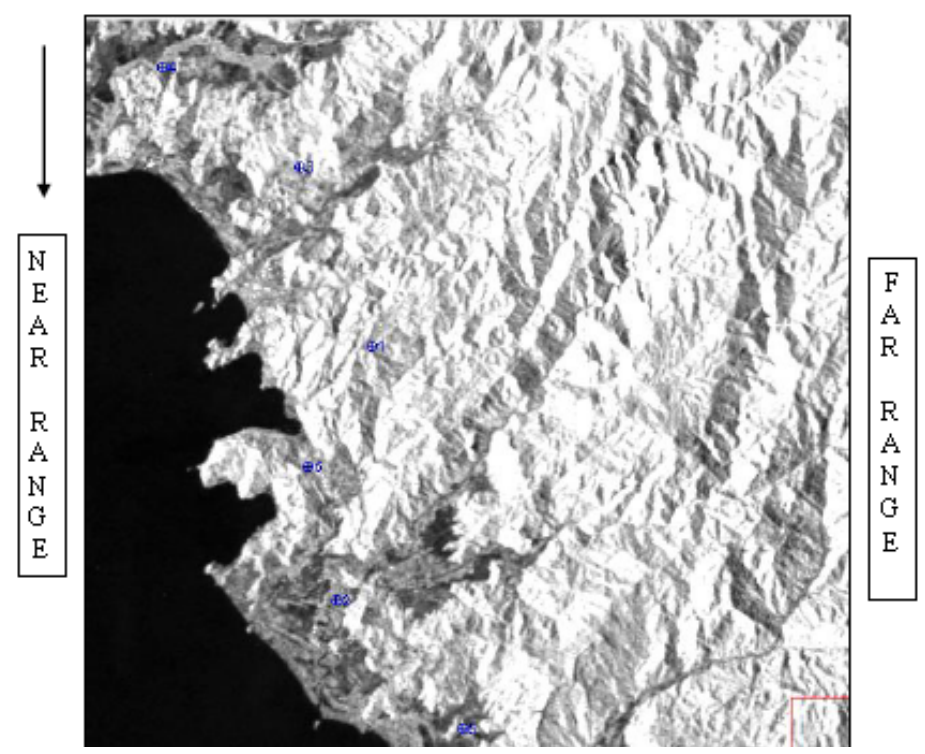

Gambar 3. Persebaran Titik GCP Transformasi Geometrik Citra Sumber: Hasil pengolahan citra ALOS PALSAR Resolusi 50 Meter

Pada setiap GCP yang ada, kemudian dilakukan perhitungan distorsi atau penyimpangan koordinat agar nilai RMSE dapat dihitung berdasarkan rumus pada persamaan 2.1. Dari hasil perhitungan RMSE, diperoleh nilai yang cukup besar yaitu 9,78 meter. Nilai RMSE yang didapat menunjukkan tingkat ketelitian hasil transformasi koordinat relatif rendah, namun demikian pada penelitian ini citra ALOS PALSAR yang diproses masih dapat digunakan untuk mengidentifikasi parameter biofisik vegetasi. Nilai RMSE yang besar diakibatkan oleh beberapa faktor antara lain resolusi citra yang rendah; sehingga menyulitkan untuk mengidentifikasi obyek pada citra. Selain itu citra ALOS PALSAR hanya memiliki band tunggal (single band) sehingga tidak dapat dilakukan komposit citra seperti citra multispektral untuk mempermudah dan meningkatkan kualitas interpretasi. Selain itu adanya efek foreshortening (pemendekan lereng) dan layover (efek rebah ke dalam) yang juga dapat berpengaruh pada keakuratan titik GCP.

\subsection{Ekstraksi Citra menggunakan NCRS}

Pengolahan citra ALOS PALSAR dengan mengubah nilai backscatter citra menjadi citra dengan satuan sigma naught $\left(\sigma^{\circ}\right)$ bertujuan agar nilai yang dihasilkan merupakan nilai koefisien backscatter pada tiap piksel citra. Nilai backscatter hasil pengolahan pada polarisasi $\mathrm{HH}$ adalah $-83 \mathrm{~dB}$ sedangkan nilai maksimumnya adalah $-59,03 \mathrm{~dB}$. Nilai backscatter hasil pengolahan pada polarisasi HV memiliki nilai minimum yaitu $-80 \mathrm{~dB}$ dan nilai maksimumnya adalah $-56,03 \mathrm{~dB}$. Nilai - nilai tersebut menunjukkan semakin tinggi nilai backscatter maka objek akan semakin cerah dan semakin rendah nilainya maka objek semakin gelap dan tidak dapat diinterpretasi. Pada Gambar 4 dapat dilihat histogram nilai backscatter pada citra hasil kalibrasi.

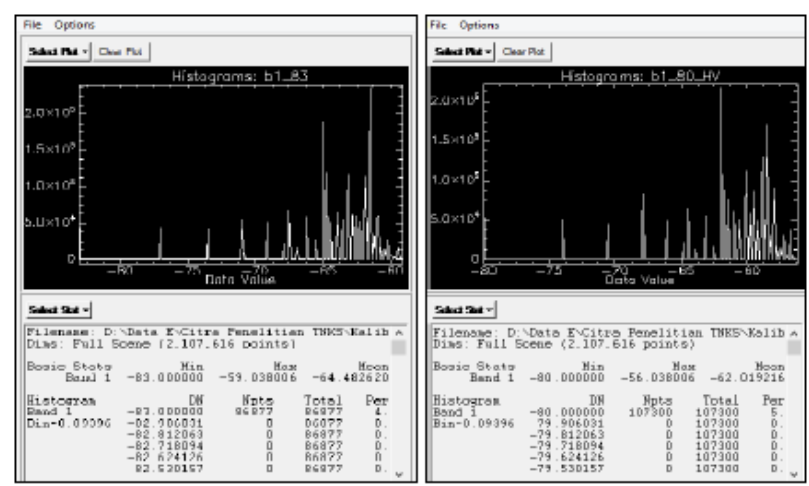

Gambar 4. Histogram Nilai Backscatter Polarisasi HH dan HV

Sumber: Hasil penqolahan citra ALOS PALSAR Resolusi 50 Meter 
Berdasarkan hasil ekstraksi citra, kemudian dilakukan pemilihan sampel untuk mengidentifikasi parameter biofisik tegakan vegetasi. Hasil identifikasi menunjukkan bahwa nilai backscatter yang tinggi pada vegetasi dengan rona yang cerah akibat adanya diffuse reflection (pantulan menyebar) dimana sinyal radar menyebar ke segala arah akan tetapi sebagian sinyal akan kembali ke sensor. Sementara objek tubuh air memberikan rona sangat gelap dan warna hitam akibat terjadinya specular reflection (pantulan cermin) dimana gelombang elektromagnetik tidak dipantulkan kembali ke wahana dan tidak ada sinyal balik yang diterima oleh sensor. Pada Gambar 5 dapat dilihat hasil kalibrasi citra ALOS PALSAR polarisasi HV di sebagian TNKS.

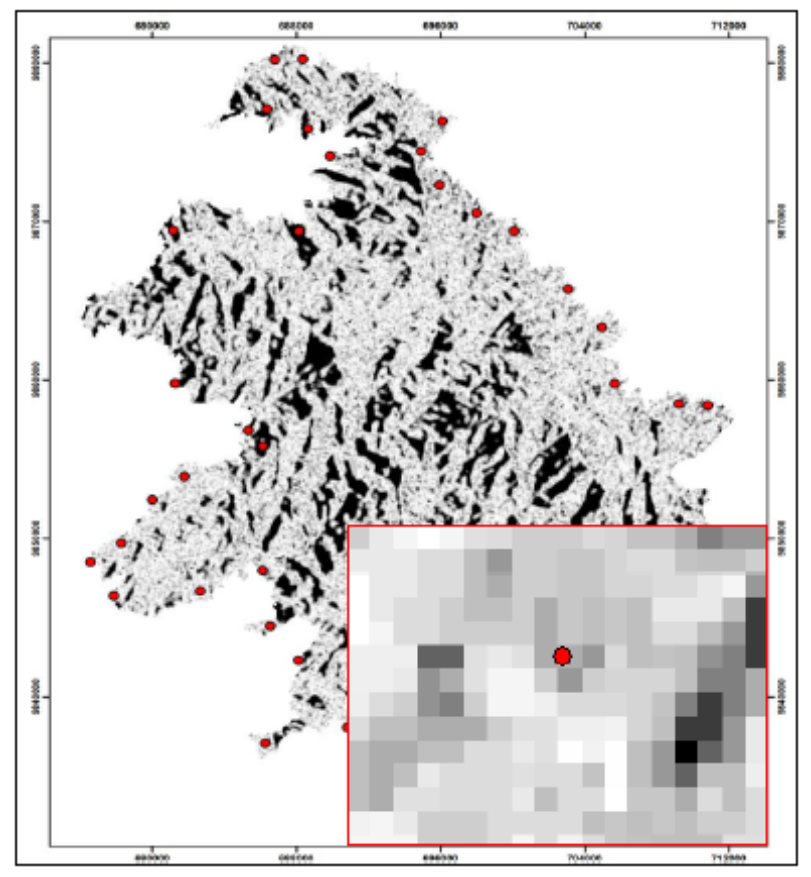

\section{Gambar 5. Hasil Ekstraksi Citra ALOS PALSAR Polarisasi HV \\ Sumber: Hasil pengolahan citra ALOS PALSAR Resolusi 50 Meter (2015)R}

\subsection{Hasil Klasifikasi Citra}

Pada penelitian ini, penggabungan dua citra ALOS PALSAR hasil polarisasi HH dan HV dilakukan terlebih dahulu sebelum tahap klasifikasi dilaksanakan dengan tujuan untuk mempertajam kecerahan objek dan mengoptimalkan kualitas citra. Kedua citra polarisasi HH dan HV ini ini dijadikan komposit citra RGB false colour dimana citra polarisasi HH ditempatkan pada band merah dan biru dan citra polarisasi HV ditempatkan pada band biru. Gabungan kedua citra menghasilkan warna kehijauan di wilayah hutan, warna ungu di daerah yang relatif datar dan warna gelap hingga hitam di wilayah tubuh air seperti sungai, pantai dan danau. Berdasarkan hasil interpretasi, jenis penutup lahan antara vegetasi kerapatan rendah hingga kerapatan tinggi tidak dapat dibedakan secara jelas, dengan demikian interpretasi hanya didasarkan pada struktur dan tekstur yang tampak pada citra. Warna ungu di wilayah yang memiliki struktur datar menghamburkan energi cukup tinggi pada polarisasi $\mathrm{HH}$ sehingga nilai backscatter yang dihasilkan pada polarisasi ini lebih tinggi. Warna kehijauan pada citra menunjukkan adanya unsur penutup lahan vegetasi karena citra hasil identifikasi polarisasi HV lebih peka terhadap vegetasi karena objek pohon yang tegak menghamburkan gelombang pada polarisasi arah vertikal sehingga nilai backscatter yang dihasilkan juga tinggi. Berdasarkan hasil klasifikasi penutup lahan hutan di TNKS, jenis penutup lahan dibagi berdasarkan Tabel 2.

Tabel 2. Klasifikasi Penutup Lahan Hutan di Taman Nasional Kerinci Seblat

\begin{tabular}{llll}
\hline Penutup Lahan & $\begin{array}{l}\text { Ketinggian } \\
\text { (mdpl) }\end{array}$ & Topografi & Habitat \\
\hline Lahan terbangun & $150-200$ & Dataran rendah & Hutan dataran rendah \\
Tubuh air & $300-800$ & Topografi & Hutan perbukitan
\end{tabular}


Hutan lahan kering

hutan lahan kering primer

Di atas 800 Pegunungan

Hutan montana

Hutan lahan kering sekunder

Sumber: Hasil Pengukuran dan Analisis Citra

Hasil klasifikasi penutup lahan di sebagian TNKS berdasarkan pengolahan citra polarisasi HH dan HV menghasilkan beberapa kelas penutup lahan yang meliputi kelas lahan terbangun, tubuh air, hutan lahan kering, hutan lahan kering primer, hutan lahan kering sekunder. Penutup lahan dijadikan dasar untuk penentuan kelas penggunaan lahan. Penggunaan Lahan di kawasan TNKS terdiri atas tiga kelas yaitu hutan lahan kering, hutan lahan kering primer, dan hutan lahan kering sekunder. Secara visual, kelas penutup lahan dan penggunaan lahan disajikan dalam Gambar 6 dan Gambar 7.

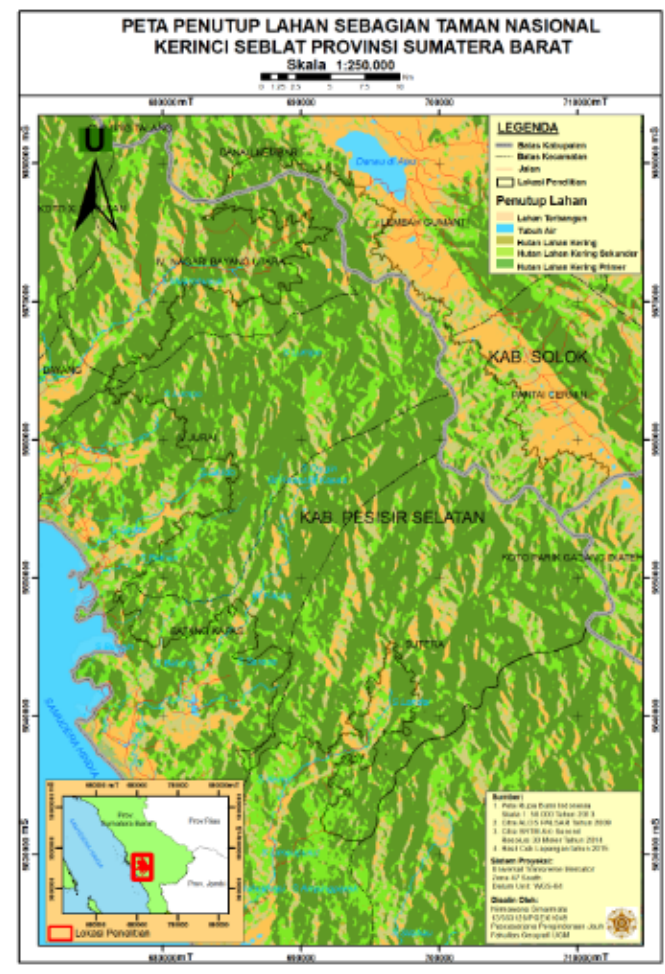

Gambar 6. Peta Penutup Lahan Sebagian Taman Nasional Kerinci

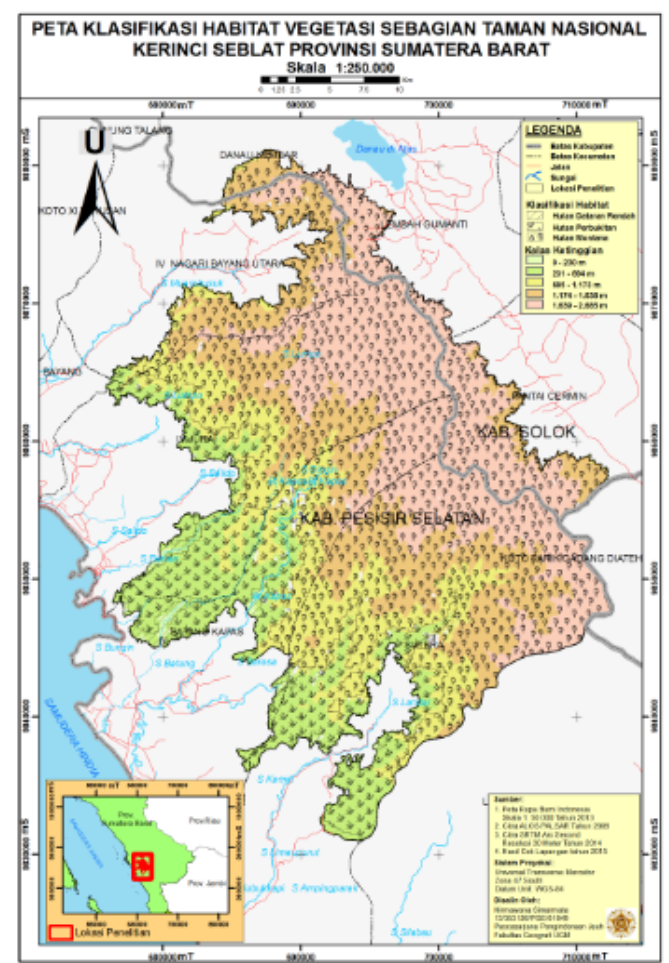

\section{Gambar 7. Peta Klasifikasi Habitat Vegetasi Sebagian TNKS}

\subsection{Karakteristik Biofisik Tegakan Vegetasi}

Nilai backscatter pada polarisasi HV memiliki korelasi yang lebih kuat terhadap parameter tegakan daripada nilai backscatter pada citra hasil polarisasi $\mathrm{HH}$. Pada habitat hutan montana di sebagian TNKS, nilai backscatter lebih tinggi daripada pada habitat hutan dataran rendah, hal ini dipengaruhi oleh kekasaran permukaan dan keanekaragaman jenis vegetasi. Permukaan yang semakin kasar akan memperoleh tone yang semakin cerah dan nilai backscatter juga akan semakin tinggi dan demikian pula sebaliknya. Berdasarkan hasil analisis menggunakan nilai backscatter dari citra hasil polarisasi $\mathrm{HH}$ dan HV menunjukkan bahwa citra hasil polarisasi HV mempunyai tingkat kepekaan yang lebih tinggi. Nilai backscatter obyek vegetasi pada topografi kasar cenderung lebih tinggi daripada topografi datar akan tetapi nilai backscatter obyek yang berada dibelakang lerengnya akan sangat kecil karena tidak memantulkan energi sama sekali. Hal ini dapat terjadi disebabkan oleh sistem perekaman citra radar yang menyamping sehingga obyek yang tidak mendapatkan energi elektromagnetik akan lebih gelap. Akurasi klasifikasi penggunaan lahan citra polarisasi $\mathrm{HH}$ diperoleh akurasi minimum sebesar $51,24 \%$ dan akurasi maksimum sebesar $62,4 \%$. Sedangkan hasil uji akurasi klasifikasi penggunaan lahan pada citra polarisasi HV diperoleh akurasi minimum sebesar $79,88 \%$ dan akurasi maksimum sebesar $74,88 \%$. Berdasarkan hasil uji akurasi tersebut menjelaskan bahwa nilai backscatter mempunyai hubungan yang kuat terhadap parameter tegakan hutan dengan persentase sebesar $62,25 \%$. 
Berdasarkan topografinya, hutan di TNKS dikelompokkan menjadi beberapa ekosistem yaitu hutan dataran rendah (lowland forest) didominasi oleh jenis vegetasi Dipterocarpus spp, Shorea atrinervosa, dan S.Multifora. Jenis vegetasi ini berasosiasi dengan Koompasia dan Anacardiaceae. Hutan dataran rendah berada pada ketinggian antara 150-200 mdpl. Hutan perbukitan (hill forest) berada pada ketinggian 300-800 mdpl yang terdapat di sisi barat dan sisi timur Bukit Barisan. Hutan perbukitan di sisi timur Bukit Barisan didominasi oleh famili Dipterocarpaceae, Fagaceae dan Burseraceae, dengan jenis yang paling banyak adalah Hopea of beccariana, sedangkan di sisi barat, didominasi oleh jenis Sterculia $s p$. Hutan ini memiliki kanopi yang relatif tinggi berkisar antara $35-40 \mathrm{~m}$. Hutan dengan ketinggian 800-1400 mdpl merupakan hutan sub-montana yang banyak ditumbuhi jenis vegetasi Myrtaceae dan Fagaceae dengan tinggi kanopi antara 25-45 m. Tipe hutan ini terdapat dua variasi bentuk hutan yaitu hutan bambu dan Garcinia. Hutan montana rendah (lower montane forest) terdapat pada ketinggian antara 1.400-1.900 mdpl.

\section{Kesimpulan}

Berdasarkan hasil pengolahan, ekstraksi citra dan klasifikasi citra diperoleh kesimpulan bahwa karakteristik backscatter citra ALOS PALSAR dengan moda fine beam Single Polarization yang meliputi polarisasi $\mathrm{HH}$ dan HV dapat dijadikan sebagai penanda parameter biofisik hutan khusunya di kawasanTNKS.

Nilai backscatter polarisasi HV memiliki korelasi yang lebih kuat terhadap parameter tegakan daripada nilai backscatter pada citra hasil polarisasi $\mathrm{HH}$.

Pada polarisasi $\mathrm{HH}$, wilayah yang memiliki struktur datar dan tekstur halus menghamburkan energi cukup tinggi sehingga nilai backscatter yang dihasilkan pada polarisasi ini lebih tinggi. Sedangkan pada polarisasi HV, wilayah dengan penutup lahan vegetasi menghamburkan gelombang pada polarisasi yang vertikal sehingga nilai backscatter yang dihasilkan tinggi.

Nilai backscatter obyek vegetasi pada topografi kasar cenderung lebih tinggi daripada topografi datar. Perbedaan pantulan setiap obyek yang ditangkap oleh sensor ALOS PALSAR menyebabkan nilai backscatter juga berbeda-beda.

\section{Daftar Pustaka}

[1] Balai Besar Taman Nasional Kerinci Seblat. 2010, Ekosistem di Taman Nasional Kerinci Seblat, http://kerinciseblat.dephut.go.id/ekosistem.html. Diakses tanggal 4 September 2014.

[2] Cartus, O,. Santoro, M., Kellndorfer., 2012, Mapping Forest Aboveground Biomass in the Northeastern United States with ALOS PALSAR DualPolarization L-Band, Remote Sensing of Environment 124 (2012) 466-478.

[3] Jensen, J. R., 1996, Introductory Digital Image Processing: A Remote Sensing Perspective. USA: Prentice Hall.

[4] Lucas, R., Armston, J., Fairfax, R., Fensham, R., Shimada, M., 2010, An Evaluation of the ALOS PALSAR L-Band Backscatter-Above Ground Biomass Relationship Queensland, Australia: Impacts of Surface Moisture Condition and Vegetation Structure, IEEE Journal of Selected Topics in Applied Earth Observations and Remote Sensing, VOL. 3, NO. 4, December 2010.

[5] Poolla, S. B., 2013, Polarimetric Scatterig model for biophysical characteristic of multilayer vegetation using space borne PoISAR Data. Enschede: Faculty of Geo-information Science and Earth Observation, University of Twente. Thesis.

[6] Shimada, M., Isoguchi, O., Tadono, T., Isono, K., 2009, PALSAR Radiometric and Geometric Calibration, IEEE Transactions on Geoscience and Remote Sensing, VOL. 47, NO. 12, December 2009.

[7] Sutanto, A., Trisakti, B., Arimurthy, A. M., 2012, Perbandingan Klasifikasi Berbasis Objek dan Klasifikasi Berbasis Piksel pada Data Citra Satelit Synthetic Aperture Radar untuk Pemetaan Lahan, Jurnal Penginderaan Jauh Vol. 11 No. 1 Juni 2014 :63-75.

[8] Suzuki, R., Kim, Y., Ishii, R., 2013, Sensitivity of the Backscatter Intensity of ALOS/PALSAR to the Above-Ground Biomass and other Biophysical Parameters of Boreal Forest in Alaska, SciVerse Science Direct. Polar Science 7 (2013) $100-112$.

[9] Trisasongko, B. H. 2012, Synthetic Aperture Radar Polarimetry, Department of Soil Science and Land Resources, Bogor: Bogor Agricultural University.

[10] Trisasongko, B. H. 2011, Autonomous Coastal Land Cover Assessment UsingPolarimetric Decomposition of SAR Data, ITB J. Eng. Sci., Vol. 43, No. 2, 2011, 101-112. 